\title{
Apremilast Application as Treatment of Oral Ulcers in Behçet Syndrome
}

\author{
Paulo Sarango-Granda ${ }^{1,3}$, Lupe Carolina Espinoza ${ }^{1,2}$, Mireia Mallandrich ${ }^{* 1,3}$ and Ana Cristina \\ Calpena $^{1,3}$ \\ ${ }^{1}$ Department of Pharmacy, Pharmaceutical Technology and Physical Chemistry, Faculty of Pharmacy and Food Sciences, \\ University of Barcelona, Spain \\ ${ }^{2}$ Departamento de Química y Ciencias Exactas, Universidad Técnica Particular de Loja, Ecuador \\ ${ }^{3}$ Institute of Nanoscience and Nanotechnology (IN2UB), University of Barcelona, Spain \\ *Corresponding author: Mireia Mallandrich, Department of Pharmacy, Pharmaceutical Technology and Physical Chemistry, Faculty \\ of Pharmacy and Food Sciences, Institute of Nanoscience and Nanotechnology (IN2UB), University of Barcelona, Spain
}

\begin{abstract}
ARTICLE INFO
Received: 蔧 March 06, 2021

Published: 幽 March 25, 2021

Citation: P Sarango-Granda, Lupe Carolina E, Mireia M, Ana Cristina C. Apremilast Application as Treatment of Oral Ulcers in Behçet Syndrome. Biomed J Sci \& Tech Res 34(5)-2021. BJSTR. MS.ID.005605.

Keywords: Behçet Disease; Behçet Syndrome; Oral Ulcers; Genital Ulcers; Apremilast; Inflammatory Disease

ABSTRACT

Several symptoms are present in the Behçet Syndrome, including oral ulcers, genital ulcers, skin lesions, eye injuries, severe problems such as meningitis, blood clots Inflammation of the digestive system and blindness can also occur. The Behçet Syndrome mainly affects countries of the Mediterranean basin, but it can also affect the Middle East, and the Far East, for instance. The prevalence in Western Europe and the United States is between 0.6 to 5.2 people per 100,000 inhabitants. The cause of Behçet Syndrome is still unknown, although some factors such as genetics, and that the environment may play a role. Currently, there is no cure for the Behçet Syndrome and the treatments are focused on alleviating the pain and preventing severe problems. Apremilast was approved by the FDA for the treatment of psoriatic arthritis and moderate to severe plaque psoriasis. Since 2019 it has also been used for the treatment of oral ulcers associated with Behçet's disease and there have been successful results in pain relief within a few weeks. However, further studies should be conducted.
\end{abstract}

Abbreviations: APR: Apremilast; AUC: Area Under The Curve; BD: Behçet Syndrome/ Behçet Disease; BDCAF: Behçet's Disease Current Activity Form; BDQOL: Behçet's Disease Quality of Life; BSAS: Behçet Syndrome Activity Score; CSs: Systemic Corticosteroids; IL: Interleukin; INF: Interferon; ISG: International Study Group; TNF $\alpha$ : Tumor Necrosis Factor-Alpha; USFDA: United States Food and Drug Administration

\section{Mini Review}

Behçet Syndrome (BD) is a disease characterized by complex, recurrent chronic and remitting inflammatory vasculitis of unknown etiology. It presents with recurrent episodes of oral, genital ulcers, skin lesions, eye injuries, among others [1], and it can cause more serious problems such as meningitis, blood clots, inflammation of the digestive system and blindness [2]. This disease can start with one or two of the symptoms indicated above, but as time passes, the rest of the symptoms are gradually triggered [3]. BD is known as the Silk Road disease because it affects all the countries of the Mediterranean Basin, the Middle East, and the
Far East, although due to migratory movements it has become universal [4]. The highest prevalence occurs in countries such as Turkey (80-370 people per 100,000 population) [5] followed by Iran (80 people per 100,000 population) [6]. In Israel, Iraq, Saudi Arabia, China and Japan the prevalence is between 11.9 and 20 people per 100,000 inhabitants [7-10], while in Western Europe and the United States the prevalence is between 0.6 to 5.2 people per 100,000 inhabitants. It is noted that the prevalence in these countries increases depending on whether people are direct descendants of Middle Eastern countries [11-14] (Figure 1). 


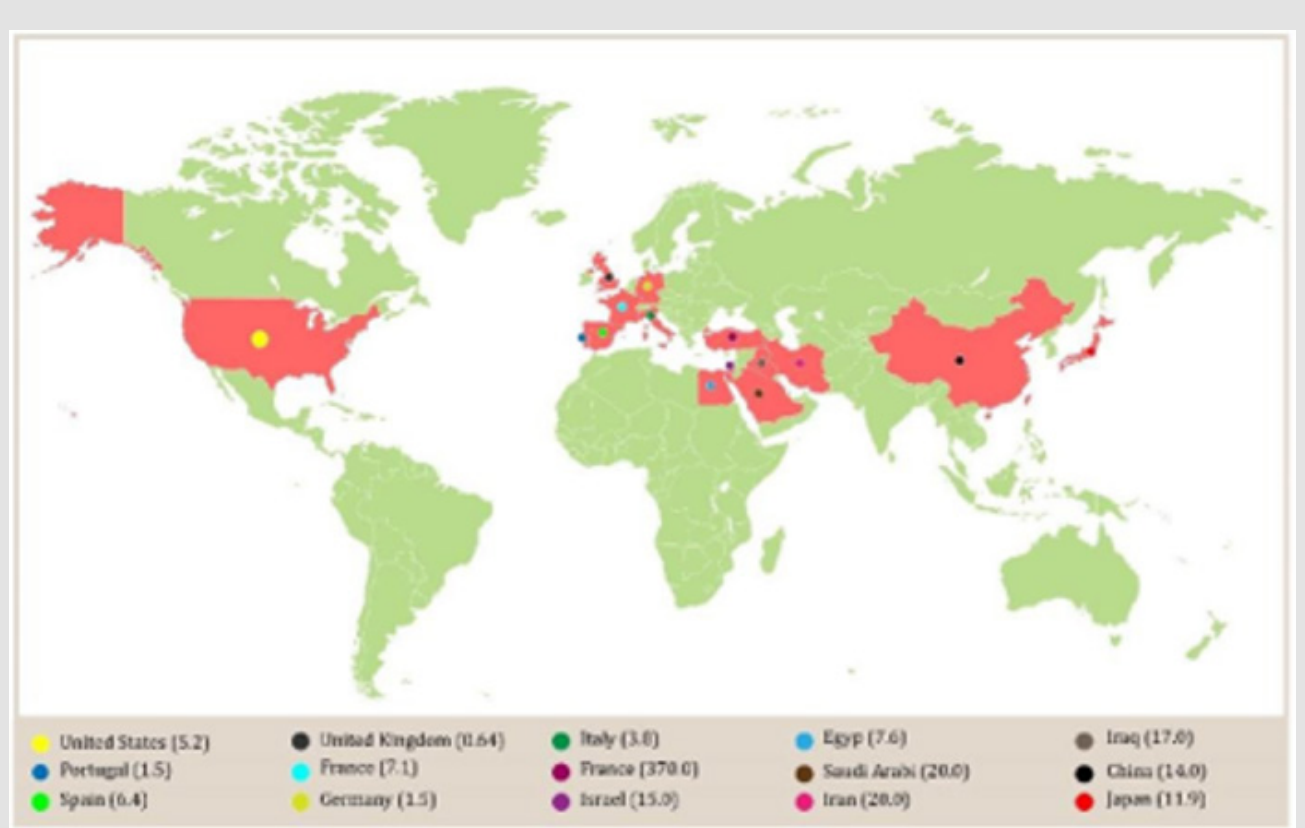

Figure 1: Prevalence of Behçet syndrome. Prevalence showed as with Behçet syndrome per 100000 of population.

Although genetic and environmental factors are directly involved in the pathogenesis of $\mathrm{BD}$, the main cause is still unknown, despite it being believed that the disease is due to an autoimmune process triggered by an infectious or environmental agent in a person who is genetically predisposed [15]. T cells have been found to be the major lymphocytes implicated in the pathogenesis of $\mathrm{BD}$, and the IL-8 produced by T cells has been correlated with disease activity (including vascular) $[16,17]$. BD has also been considered an autoinflammatory disease [18] and this is corroborated due to the similarities with Crohn's Disease, which is considered an autoinflammatory disease $[19,20]$. A genome study conducted in BD patients reported an association for BD of Interleukin 4 (IL4), Intelerukin 10 (IL-10), Interleukin 12 (IL-12), Interleukin 13 (IL-13), Interferon- $\gamma$ (INF- $\gamma$ ) and IL23R - IL12RB2 loci. Similarly, two associations were identified in the 1p31.3 (IL23R-IL12RB2) and 1q32.1 (IL10) chromosomes, which predispose people with BD [21,22]. BD is associated with a range between IL23R and IL12RB2. An increase in Th1, Th17, CD4 + and CD8 + T cells was also found, and activity was observed in $\gamma \delta+\mathrm{T}$ cells in both serum and tissues of diagnosed patients with $\mathrm{BD}$, suggesting that innate and adaptive immunity are involved in the pathogenesis of this disease $[23,24]$. The diagnosis of BD is not easy to detect in patients with oligosymptomatology. However, many authors apply their criteria or a combination thereof with the diagnostic criteria issued by the International Study Group (ISG). These criteria consist of the identification of clinical characteristics such as oral ulcers, genital ulcers, eye injuries, skin lesions and the pathergy test (Table 1). $97-99 \%$ of the cases detected with BD, mucocutaneous lesions represent the distinctive clinical manifestation, and genital ulcerations represent 85\% [25-27].

Table 1: International Study Group Diagnostic Criteria for Behçet's Disease. Adapted from [25].

\begin{tabular}{|c|c|}
\hline Criteria & Descriptions \\
\hline Recurrent oral ulcerations & $\begin{array}{l}\text { Minor aphthous, major aphthous, or herpetiform ulceration observed by physician or patient, which } \\
\text { recurred at least } 3 \text { times in one 12-month period. }\end{array}$ \\
\hline \multicolumn{2}{|c|}{ Plus 2 of the Following Criteria in the Absence of Other Clinical Explanations: } \\
\hline Recurrent genital ulceration & Aphthous ulceration or scarring, observed by physician or patient. \\
\hline Eye lesions & $\begin{array}{c}\text { Anterior uveitis, posterior uveitis, or cells in vitreous on slit-lamp examination; or retinal vasculitis } \\
\text { observed by an ophthalmologist. }\end{array}$ \\
\hline Skin lesions & $\begin{array}{l}\text { Erythema nodosum observed by physicians or patients, pseudo-folliculitis, or papulopustular lesions; or } \\
\text { Acneiform nodules observed by physician in post- adolescent patients, not on corticosteroid treatment. }\end{array}$ \\
\hline Positive pathergy test & Read by a physician at $24-48 \mathrm{~h}$. \\
\hline
\end{tabular}

Currently, there is no cure for BD, however, there have been studies with various drugs to focus treatment on reducing pain and preventing more serious problems. For example, first-line therapy for the treatment of clinical manifestations such as mucocutaneous injuries includes colchicine and corticosteroids $[28,29]$ has come forward. The effect of colchicine has been evaluated in some studies 
for the treatment of BD. In one carried out by Davatchi et al with a total of 169 patients who met the international criteria for Behçet's disease, they were administered colchicine $(1 \mathrm{mg} /$ tablet $)$ at night for 4 months. Patients were randomized to colchicine or placebo; the results showed an improvement in oral and genital ulcers, pseudofolliculitis and erythema nodosum in patients who were treated with colchicine, that is, this drug significantly improved overall symptoms of the disease [30]. Systemic Corticosteroids (CSs) in many cases have been used for the treatment of BD, it is the case of Prednisolone that is used in doses of $0.5-1 \mathrm{mg} / \mathrm{kg}$ [31]. In a study carried out with 54 prescribed patients with intestinal BD, they were treated with CS and showed encouraging results due to complete remission of the disease in $46.3 \%$ of cases, unfortunately, after one year, $35.2 \%$ of patients showed corticosteroid dependence [32]. Corticosteroids are used to treat several of the manifestations of BD. However, many patients become resistant or dependent. Alpsoy et al determined the therapeutic efficacy of interferon $\alpha-2 \mathrm{a}$ for the treatment of $\mathrm{BD}$, especially for mucocutaneous lesions, demonstrating its effectiveness [33]. Lesions that are resistant to these treatments include azathioprine, rituximab, rebamipide [3437]. In addition, immunosuppressive drug combined therapies are used as they have demonstrated to be effective as interferon- $\alpha$ (INF- $\alpha$ ), thalidomide, and blocking agents of tumor necrosis factoralpha (TNF $\alpha)$ such as infliximab [38].

\section{Apremilast as Treatment of Oral Ulcers Manifested in Behçet Syndrome}

Apremilast (APR) is a small molecule approved by the United States Food and Drug Administration (USFDA) for the treatment of adults with psoriatic arthritis and moderate to severe plaque psoriasis and since 2019 it has been approved for the treatment of oral ulcers associated with Behçet's disease [39]. Clinical studies developed with apremilast have demonstrated its efficacy and safety against oral ulcers in BD patients [40]. A phase II clinical trial conducted in hospitals in Turkey and the United States between 2009 and 2011, with a total of 111 patients who met the criteria of the International Group for Behçet's Disease, mean age of between $37.3 \pm 0.4$ and a mean number of oral ulcers per patient at the start of the study of $3.1 \pm 1.3$ in the APR group and $3.2 \pm 2.1$ in the placebo group. Treatment consisted of the $30 \mathrm{mg}$ dose of apremilast twice a day for 12 weeks and thereafter a 28-day observation after treatment. As a result, a significant reduction of oral ulcerations was obtained in the group treated with APR as opposed to the placebo group $(0.5 \pm 1.0$ vs. $2.1 \pm 2.6, p<0.001)$ [41-44]. Subsequently, between 2014 and 2017, a global study was conducted involving 53 centers in 10 countries that included Asia, Europe, the United States, Israel, Lebanon and Turkey. A total of 207 prescribed BD patients participated and in a 1:1 ratio they were randomly administered $30 \mathrm{mg}$ of APR twice daily and placebo, for 12 weeks. This trial allowed the evaluation of the efficacy, tolerability and safety of APR. The main endpoint was the Area Under The Curve (AUC) for the number of oral ulcers up to 12 weeks. As a result, a significantly lower number of these ulcers was obtained for the group treated with APR compared to the control group, also, the reduction in pain evidenced the efficacy of the drug in the first weeks of treatment. Nausea, vomiting, abdominal pain, and diarrhea were some of the adverse reactions that the group treated with APR presented [45-47]. Recent studies carried out by Luca et al evaluated the efficacy and safety of Apremilast in 12 patients with BD who had recurrent ulcerations and/or intolerance to conventional therapies. Those who had uveitis and gastrointestinal involvement were excluded. The study demonstrated the efficacy of apremilast for oral ulcers and overall disease activity based on the Behçet Syndrome Activity Score (BSAS), Behçet's Disease Current Activity Form (BDCAF), Visual Analog Scale (VAS) and changes in the Behçet's Disease Quality of Life (BDQOL) at week 12. Diarrhea in three patients and suicidal ideation in one were the main adverse effects that occurred, which limited the study, so it was decided to suspend administration [48]. A retrospective study carried out by Lopalco et al in Italy, demonstrated the effectiveness of apremilast in obtaining clinical results similar to Luca et al, in 13 patients with BD who presented oral and genital ulcers refractory to multiple treatments, including TNF inhibitors [49].

\section{Conclusion}

Due to the nature of Behçet's disease, the studies carried out with apremilast suggest its employability in the treatment. However, it is necessary to carry out long-term studies and also evaluate other possible pharmaceutical forms and administration routes of the drug to improve its bioavailability.

\section{Acknowledgement}

We thank the Institute of Nanoscience and Nanotechnology (IN2UB) of the University of Barcelona for their support. The authors also want to thank Harry Paul for the English Language Editing.

\section{Conflicts of Interest}

There are no conflicts of interest to declare.

\section{References}

1. Emmi G, Bettiol A, Silvestri E, Di Scala G, Becatti M, et al. (2019) Vascular Behçet's Syndrome: An Update. Intern Emerg Med 14 (5): 645-652.

2. Nair J, Moots R (2017) Behcet's Disease. Clinical Medicine 17(1): 71-77.

3. Arayssi T (2004) New Insights into the Pathogenesis and Therapy of Behçet's Disease. Current Opinion in Pharmacology 4(2): 183-188.

4. Yazici H, Seyahi E, Hatemi G, Yazici Y (2018) Behçet Syndrome: A Contemporary View. Nat Rev Rheumatol 14(2): 107-119.

5. Ceylan Kalın Z, Sarıcaoğlu H, Yazici S, Aydoğan K, Bülbül Bașkan E (2019) Clinical and Demographical Characteristics of Familial Behçet's Disease (Southeast Marmara Region). Dermatology 235(5): 407-412. 
6. Davatchi F, Shahram F, Chams-Davatchi C, Shams H, Abdolahi BS, et al. (2019) Behcet's Disease in Iran: Analysis of 7641 Cases. Modern Rheumatology 29(6): 1023-1030.

7. Muhaya M, Lightman S, Ikeda E, Mochizuki M, Shaer B, et al. (2000) Behçet's Disease in Japan and in Great Britain: A Comparative Study. Ocul Immunol Inflamm 8(3): 141-148.

8. Chen Y, Cai J-F, Lin C-H, Guan J-L (2019) Demography of Vascular Behcet's Disease with Different Gender and Age: An Investigation with 166 Chinese Patients. Orphanet J Rare Dis 14(1): 88.

9. Alkazzaz AMH, Ebdan WR, Ghoben Mustafa K, Kareem ZT, Al-Harbi SJO (2020) Behçet's Disease in Iraq: New Insights into the Clinical and Epidemiologic Features in Middle-Euphrates Region. Expert Review of Clinical Immunology 16(1): 109-112.

10. Liu X, Gao F, Zhao C, Zhang M (2020) Clinical Features of Patients with Behcet's Uveitis. Chinese Journal of Ophthalmology 56(3): 217-223.

11. Sota J, Rigante D, Emmi G, Lopalco G, Orlando I, et al. (2020) Behçet's Syndrome in Italy: A Detailed Retrospective Analysis of 396 Cases Seen in 3 Tertiary Referral Clinics. Intern Emerg Med 15(6):1031-1039.

12. Wessman LL, Andersen LK, Davis MDP (2018) Incidence of Diseases Primarily Affecting the Skin by Age Group: Population-Based Epidemiologic Study in Olmsted County, Minnesota, and Comparison with Age-Specific Incidence Rates Worldwide. Int J Dermatol 57(9): 1021-1034.

13. Toledo-Samaniego N, Galeano-Valle F, Ascanio-Palomares P, GonzálezMartínez B, Valencia-Kruszyna A, et al. (2020) Manifestaciones neurológicas en la enfermedad de Behçet: estudio de 57 pacientes. Medicina Clínica 154(12): 488-492.

14. Borhani-Haghighi A, Kardeh B, Banerjee S, Yadollahikhales G, Safari A, et al. (2020) Neuro-Behcet's Disease: An Update on Diagnosis, Differential Diagnoses, and Treatment. Multiple Sclerosis and Related Disorders 39: 101906.

15. Pay S, Şimșek İ, Erdem H, Dinç A (2007) Immunopathogenesis of Behçet's Disease with Special Emphasize on the Possible Role of Antigen Presenting Cells. Rheumatol Int 27(5): 417-424.

16. Greco A, De Virgilio A, Ralli M, Ciofalo A, Mancini P, et al. (2018) Behçet's Disease: New Insights into Pathophysiology, Clinical Features and Treatment Options. Autoimmunity Reviews 17(6): 567-575.

17. Zouboulis ChC, Katsantonis J, Ketteler R, Treudler R, Kaklamani E, et al. (2000) Adamantiades-Behçet's Disease: Interleukin-8 Is Increased in Serum of Patients with Active Oral and Neurological Manifestations and Is Secreted by Small Vessel Endothelial Cells. Archives of Dermatological Research 292(6): 279-284.

18. Gül A (2005) Behçet's Disease as an Autoinflammatory Disorder. Curr Drug Targets Inflamm Allergy 4(1): 81-83.

19. Valenti S, Gallizzi R, De Vivo D, Romano C (2017) Intestinal Behçet and Crohn's Disease: Two Sides of the Same Coin. Pediatr Rheumatol 15(1): 33.

20. Direskeneli H (2006) Autoimmunity vs Autoinflammation in Behcet's Disease: Do We Oversimplify a Complex Disorder? Rheumatology 45(12): 1461-1465.

21. Mizuki N, Meguro A, Ota M, Ohno S, Shiota T, et al. (2010) GenomeWide Association Studies Identify IL23R-IL12RB2 and IL10 as Behçet's Disease Susceptibility Loci. Nat Genet 42(8): 703-706.

22. Aridogan BC, Yildirim M, Baysal V, Inaloz HS, Baz K, et al. (2003) Serum Levels of IL-4, IL-10, IL-12, IL-13 and FN-Gamma in Behçet's Disease. The Journal of Dermatology 30(8): 602-607.

23. Cho JH, Brant SR (2011) Recent Insights Into the Genetics of Inflammatory Bowel Disease. Gastroenterology 140(6): 1704-1712.
24. Remmers EF, Cosan F, Kirino Y, Ombrello MJ, Abaci N, et al. (2010) Genome-Wide Association Study Identifies Variants in the MHC Class I, IL10, and IL23R-IL12RB2 Regions Associated with Behçet's Disease. Nat Genet 42(8): 698-702.

25. (1990) International Study Group for Behcet's Disease. Criteria for Diagnosis of Behcet's Disease. The Lancet 335(8697): 1078-1080.

26. Kaklamani VG, Vaiopoulos G, Kaklamanis PG (1998) Behçet's Disease. Semin Arthritis Rheum 27(4): 197-217.

27.Al-Araji A, Kidd DP (2009) Neuro-Behçet's Disease: Epidemiology, Clinical Characteristics, and Management. The Lancet Neurology 8(2): 192-204.

28. Cabras M, Carrozzo M, Gambino A, Broccoletti R, Sciascia S, et al. (2020) Value of Colchicine as Treatment for Recurrent Oral Ulcers: A Systematic Review. J Oral Pathol Med 49(8): 731-740.

29. Djaballah-Ider F, Touil-Boukoffa C (2020) Effect of Combined ColchicineCorticosteroid Treatment on Neutrophil/Lymphocyte Ratio: A Predictive Marker in Behçet Disease Activity. Inflammopharmacol 28(4): 819-829.

30. Davatchi F, Sadeghi Abdollahi B, Tehrani Banihashemi A, Shahram F, Nadji A, et al. (2009) Colchicine versus Placebo in Behçet's Disease: Randomized, Double-Blind, Controlled Crossover Trial. Modern Rheumatology 19(5): 542-549.

31. Kim DH, Cheon JH (2016) Intestinal Behçet's Disease: A True Inflammatory Bowel Disease or Merely an Intestinal Complication of Systemic Vasculitis? Yonsei Med J 57(1): 22-32.

32. Park JJ, Kim WH, Cheon JH (2013) Outcome Predictors for Intestinal Behçet's Disease. Yonsei Med J 54(5): 1084-1090.

33. Alpsoy E, Durusoy C, Yilmaz E, Ozgurel Y, Ermis O, et al. (2002) Interferon Alfa-2a in the Treatment of Behçet Disease: A Randomized PlaceboControlled and Double-Blind Study. Arch Dermatol 138(4): 467-471.

34. Melikoglu M, Fresko I, Mat C, Ozyazgan Y, Gogus F, et al. (2005) ShortTerm Trial of Etanercept in Behçet's Disease: A Double Blind, Placebo Controlled Study. J Rheumatol 32(1): 98-105.

35. Matsuda T, Ohno S, Hirohata S, Miyanaga Y, Ujihara H, et al. (2003) Efficacy of Rebamipide as Adjunctive Therapy in the Treatment of Recurrent Oral Aphthous Ulcers in Patients with Behçet's Disease. Drugs R\&D 4(1): 19-28.

36. Saleh Z, Arayssi T (2014) Update on the Therapy of Behçet Disease. Therapeutic Advances in Chronic Disease 5(3): 112-134.

37. Yazici H, Pazarli H, Barnes CG, Tüzün Y, Özyazgan Y, et al. (1990) A Controlled Trial of Azathioprine in Behçet's Syndrome. The New England Journal of Medicine 322(5): 281-285.

38. Arida A, Fragiadaki K, Giavri E, Sfikakis PP (2011) Anti-TNF Agents for Behçet's Disease: Analysis of Published Data on 369 Patients. Seminars in Arthritis and Rheumatism 41(1): 61-70.

39.Zerilli T, Ocheretyaner E (2015) Apremilast (Otezla): A New Oral Treatment for Adults with Psoriasis and Psoriatic Arthritis. Drug Forecast 40(8): 495-500.

40. Takeno M (2020) Positioning of Apremilast in Treatment of Behçet's Disease. Modern Rheumatology 30(2): 219-224.

41. Hatemi G, Melikoglu M, Tunc R, Korkmaz C, Turgut Ozturk B, et al. (2015) Apremilast for Behçet's Syndrome-A Phase 2, Placebo-Controlled Study. N Engl J Med 372(16): 1510-1518.

42. Giácaman von der Weth MM, Tapial JM, Guillén BF, Ferrer DS, SánchezCarazo JL, et al. (2020) Complex Aphthae Treated With Apremilast. JCR: Journal of Clinical Rheumatology 26(3): e69-e70.

43. Cetin Gedik K, Romano M, Berard RA, Demirkaya E (2020) An Overview of Conventional and Recent Treatment Options for Behcet's Disease. Curr Treat Options in Rheum 6(17). 
44. Maloney NJ, Zhao J, Tegtmeyer K, Lee EY, Cheng K (2020) Off-Label Studies on Apremilast in Dermatology: A Review. Journal of Dermatological Treatment 31(2): 131-140.

45. Hatemi G, Mahr A, Ishigatsubo Y, Song Y-W, Takeno M, et al. (2019) Trial of Apremilast for Oral Ulcers in Behçet's Syndrome. N Engl J Med 381(20): 1918-1928.

46. Leccese P, Ozguler Y, Christensen R, Esatoglu SN, Bang D, et al. (2019) Management of Skin, Mucosa and Joint Involvement of Behçet's Syndrome: A Systematic Review for Update of the EULAR Recommendations for the Management of Behçet's Syndrome. Seminars in Arthritis and Rheumatism 48(4): 752-762.

ISSN: 2574-1241

DOI: 10.26717/BJSTR.2021.34.005605

Mireia Mallandrich. Biomed J Sci \& Tech Res

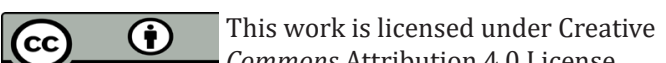

Submission Link: https://biomedres.us/submit-manuscript.php
47. Onuora S (2020) Apremilast Reduces Behçet Oral Ulcers. Nature Reviews Rheumatology 16(2): 62.

48. De Luca G, Cariddi A, Campochiaro C, Vanni D, Boffini N, et al. (2020) Efficacy and Safety of Apremilast for Behçet's Syndrome: A Real-Life Single-Centre Italian Experience. Rheumatology 59(1): 171-175.

49. Lopalco G, Venerito V, Leccese P, Emmi G, Cantarini L, et al. (2019) Real-World Effectiveness of Apremilast in Multirefractory Mucosal Involvement of Behçet's Disease. Ann Rheum Dis 78(12): 1736-1737.

BIOMEDICAL
RESEARCHES $\quad \begin{aligned} & \text { Assets of Publishing with us } \\ & \text { - Global archiving of articles }\end{aligned}$

